\title{
Vegetation Impact on Microclimate in Hot Climate Zones
}

\author{
Abeer Manneh, Hanan Taleb \\ Sustainable Design of the Built Environment, the British University in Dubai \\ Dubai, UAE \\ abeermanneh@hotmail.com; hanan.taleb@buid.ac.ae
}

\begin{abstract}
Computational modelling has been used to investigate the impact of vegetation on the microclimate in a campus courtyard in Qatar. Sixteen scenarios were tested during a hot day with over twenty thousand data entry points analysed for Air Temperature, Wind Speed, Mean Radiant Temperature and Predicted Mean Vote parameters. Trees provide direct shading, evapotranspiration and wind shielding which impacts thermal comfort conditions experienced locally as well as mitigating heat island effect. Vegetation has the ability to reduce excessive air temperature through sunlight interception. Its geometric configuration influences the amount of solar radiation, air temperature, humidity and wind velocity on microclimate of a given area. The study indicates that an equally distributed vegetation cover results in improved thermal comfort and a significant MRT reduction of $28.3^{\circ} \mathrm{C}$ within the courtyard. The arrangement provides MRT improvement of $7.4^{\circ} \mathrm{C}$ compared to the baseline scenario. The vegetation type also impacts the microclimate where trees of the same leaf density and higher trunk result in an increase of $0.2 \mathrm{~m} / \mathrm{s}$ in wind speed. The shaded grass areas witness a reduction of $1.1^{\circ} \mathrm{C}$ of air temperature and $22^{\circ} \mathrm{C}$ surface temperature compared to exposed hardscape. When replacing trees by shading structures, an increase of $3-5^{\circ} \mathrm{C}$ MRT is witnessed along with an increase in reflected solar radiation. The study concluded that the placement of trees in a configuration that allows air movement and provision of shading as well as having an equally distributed vegetation cover are key to reduce both short-wave and long-wave radiation, avoid solar absorption and heat being trapped in the space.
\end{abstract}

Keywords: Microclimate, predicted mean vote, outdoor thermal comfort, urban development, vegetation

\section{Introduction}

The contribution of urbanization towards global warming and its relation to Urban Heat Island (UHI) effect has been widely investigated in the past decade. Major cities which are largely developed such as Sydney, Tokyo and Brussels attributes its global warming impact to the increase of green-house gases rather than being caused by urbanization. [1,2,3]

However, in emerging cities, urbanization can be one of the main contributors to UHI effect. In the United States, urban sprawl and the lack of adaptive design are expected to increase near-surface temperature between $1-2^{\circ} \mathrm{C}$ by 2100 [4].

Global warming and urbanization are also expected to increase the global air temperature by $2-4^{\circ} \mathrm{C}$ by 2100 [5].

The impact of urbanization level is highly correlated to the urban thermal environment [6,7]. While indoor and outdoor thermal comfort is key to occupant's utilization of the space, achieving outdoor thermal comfort is critical to human health and increased activity level through encouraging citizens to use the outdoor open spaces. [8,9]

Many studies were conducted to understand the parameters impacting human thermal comfort and establishing models to describe this relation. Physical and physiological parameters are explained in various models which can be categorized under thermal models, metrical and linear models [10]. One of the earliest and most recognized models was established by Franger in 1972 Predicted Mean Vote (PMV) which was based on a controlled indoor environment. The model was later modified and is recognized by the International Organization for Standardization described under ISO 7730 [10], [11]. Another widely used model is Physiological Equivalent Temperature (PET) which was based on Munich Energy-Balance Model for Individuals [12] and was later adapted for several climate zones. However, the model that has been adapted to all climatic zones is the Universal Thermal Climatic Index (UTCI) which is developed based on a multi-node dynamic thermophysiological model capable of measuring thermal effect on whole and parts of the human body. UTCI is also the only energy balance model that has been used for all scales from micro to macro urban scale.

All three thermal indices use the climatic parameters: Air Temperature (Ta), Relative Humidity (RH), Wind Speed 
(V), the microclimate parameters represented by the virtual temperature of Mean Radiant Temperature (MRT) and human parameters represented by clothing $(\mathrm{Cl})$. Both PMV and PET also take into consideration the human parameter of Metablic Rate (Ma). PET also takes into consideration global radiation impact [10,13,14]

For the purpose of relating the thermal impact of the built environment on humans, measuring MRT is essential to translate the thermal radiation into a virtual measurement by taking into consideration short-wave radiation and long-wave radiation of the environment. Short-wave radiation - direct, diffused and reflected- is primarily related to the solar radiation hence the shading highly impacts MRT. However, for long-wave radiation, environmental and atmospheric conditions from the surrounding is the key influencer. A recent study by Lai et.al highlighted the increase of $10 \mathrm{~W} / \mathrm{m} 2$ for either longterm or short-term radiation results in MRT increase of $1.6^{\circ} \mathrm{K}$ [15]. The impact of vegetation on cooling outdoor thermal environments has been investigated by many researchers where vegetation results in reduction of surface temperature, air temperature and improved thermal comfort $[5,15,16,17,18,19]$.

A study in Sao Paolo, Brazil during an extremely warm Summer day indicated that a drop in air temperature of $0.6^{\circ} \mathrm{C}$ when largely dense street trees are introduced to a highly dense urban block would result in a larger impact of thermal comfort. Whereas surface temperature is reduced by $16^{\circ} \mathrm{C}$ through introduction of vegetation. [17]. Another study in Hong Kong conducted in a typically hot day investigated the impact of vegetation pattern on thermal comfort, where it indicates that a double-row tree configuration for streets results in higher difference in PET when compared to a single centred row of trees [5]. The findings by Lai et.al explains that long-wave radiation from surrounding environment can be as critical as short-wave radiation if Solar View Factor SVF is high. In other words, although shading can block the short-wave radiation from the sun, the heat absorption from the surrounding environment can increase the MRT due to increased longwave radiation [15]. The impact of trees on MRT is explained by Robitu et.al where the radiative transfer of the tree is seen as complex as the tree can reflect part of the incident radiation, absorb another, transmit part onto the surrounding environment and penetrates a fraction through its canopy [16].

\section{Methodology}

\subsection{Research Tool}

This research aims at assessing the impact of vegetation on outdoor thermal comfort using an existing development in Doha, Qatar. In order to assess multiple scenarios of softscape and hardscape arrangements, computer simulation is considered the most viable research method when compared to actual intervention and experimental approach. According to Cheshmehzangi 2016 [20] Computational Fluid Dynamic (CFD) tools can greatly inform the design process when utilized in an integrated process along three stages: pre-concept, design development and final design stage.

There are several tools that are currently used for thermodynamics analysis such as IES VE, VISARI and Envi-Met. Envi-Met v4.1.0 Winter16/17 built on November 2016 is used for this research. Envi-Met is a three-dimensional microclimate analysis tool [21]. The key feature of Envi-Met that makes it useful for this research is the ability to model the plant-surface-atmospheric interactions; taking into consideration evapotranspiration impact of vegetation [22]. When compared to IES and Vasari, Envi-met performs better in terms of solar radiation, humidity, wind and air movement and surface albedo characteristics analysis. [23]

Although many researchers have investigated the accuracy of Envi-Met v3.1, there is limited research conducted to assess version 4 of the software. Lim and Roth suggest that Envi-Met is a helpful tool for urban design and planning where diurnal air temperature is comparable to field measurements. Similarly, mean radiant temperature MRT variables results can be considered satisfactory using this tool. The researcher suggests that peak MRT is well predicted with a general observation that temperature results are more accurate during wet rather than dry days [24].

\subsection{Envi-Met Model}

The baseline model is built based on the existing setting of College of North Atlantic- Qatar, Doha (CNAQ) as shown in Fig 1 - 2. The campus is built over a 400,000sm site area and accommodates a gross floor area of $80,000 \mathrm{sm}$ which has been designed on a grid of $4.5 \mathrm{~m} \times 9 \mathrm{~m}$. Buildings are generally two stories with ranging height from $10 \mathrm{~m}$ to $13 \mathrm{~m}$ on average.

The focus area of study is the main courtyard within the campus which is mostly unshaded with a total area of 2,064sm and clear dimensions of around 36m x 56m -highlighted in in red Fig. 2. 


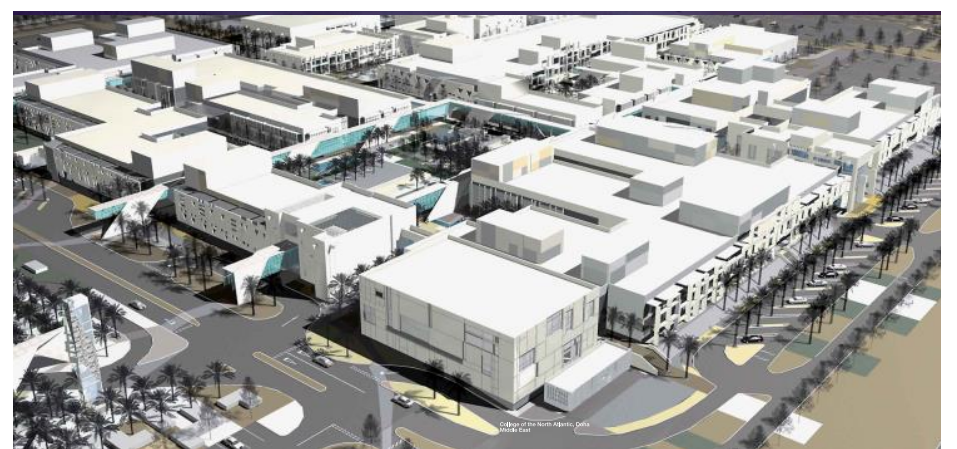

Fig. 1: Three-dimensional model of College of North Atlantic - Qatar.

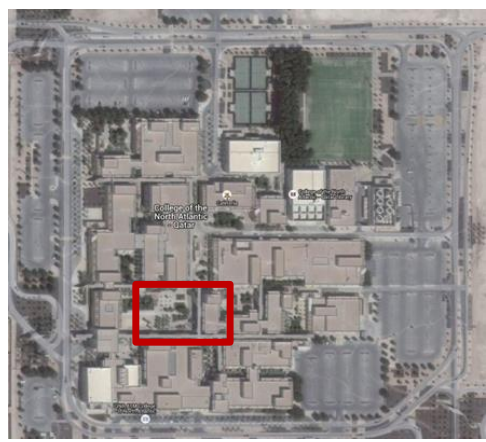

Fig. 2: College of North Atlantic - Qatar aerial view.

The research considers multiple scenarios of vegetation types, arrangement, hardscape and shading. Sixteen scenarios are modelled and analysed as indicated in Table 1 and are simulated for two hours a year which are $14^{\text {th }}$ October at 10 am and $12 \mathrm{am}$. The results analysed using four indicators: PMV, Ta, MRT and V which add up to a total of 64 scenarios and 256 indicators. The analysis was based on 20,416 data entries extracted from Envi-Met model. The model is cut at $\mathrm{z}=1.4 \mathrm{~m}$ to represent an occupied zone for temperature and wind parameters, and calculated up to $1.8 \mathrm{~m}$ for PMV assessment.

Table 1: Simulation models summary.

\begin{tabular}{|c|c|c|c|c|c|c|}
\hline \multirow{2}{*}{$\begin{array}{l}\text { Simulation } \\
\text { Number }\end{array}$} & \multirow[t]{2}{*}{ Scenario } & \multirow[t]{2}{*}{ Description } & \multicolumn{4}{|c|}{ Softscape vs. Hardscape } \\
\hline & & & $\begin{array}{c}\text { Tree } \\
(\mathrm{SK}) \\
\#\end{array}$ & $\begin{array}{c}\text { Tree } \\
\text { (T1) } \\
\#\end{array}$ & $\begin{array}{c}\text { Grass } \\
\text { (XX) } \\
\text { Sq.M. }\end{array}$ & $\begin{array}{l}\text { Hardscape } \\
\text { Sq.M }\end{array}$ \\
\hline 1 & Baseline & Model as per existing conditions & 1 & 43 & 212 & 1676 \\
\hline 2 & Grass & Replacing all baseline vegetation with grass type & 0 & 0 & 388 & 1676 \\
\hline 3 & Hardscape & Replacing all vegetation with hardscape & 0 & 0 & 0 & 2064 \\
\hline 4 & Vegetation SK & Replacing $10 \mathrm{~m}$ trees by $15 \mathrm{~m}$ trees & 44 & 0 & 212 & 1676 \\
\hline 5 & $\begin{array}{l}\text { Shading } \\
\text { Structure }\end{array}$ & $\begin{array}{l}\text { Replacing trees by shading structure at } 3 \mathrm{~m} \text { height with } \\
\text { grass below }\end{array}$ & 0 & 0 & 388 & 1676 \\
\hline 6 & $\begin{array}{l}\text { Additional } \\
\text { Shading }\end{array}$ & $\begin{array}{l}\text { Additional } 820 \mathrm{sm} \text { perimeter shading and } 228 \mathrm{sm} \\
\text { shading within the courtyard at } 7 \mathrm{~m} \text { height }\end{array}$ & 0 & 0 & 388 & 1676 \\
\hline 7 & $\begin{array}{l}\text { Vegetation } \\
\text { Pattern } 1\end{array}$ & $\begin{array}{l}\text { Alternative vegetation configuration using the same } \\
\text { types and number of plants as the baseline }\end{array}$ & 1 & 43 & 212 & 1676 \\
\hline 8 & $\begin{array}{l}\text { Vegetation } \\
\text { Pattern } 2\end{array}$ & $\begin{array}{l}\text { Same configuration as vegetation pattern } 1 \text { with } \\
\text { replacing } \mathrm{T} 1 \text { by } \mathrm{SK} \text { trees }\end{array}$ & 44 & 0 & 212 & 1676 \\
\hline
\end{tabular}

Vegetation types used for this study are as indicated in Table 2 below. Hardscape specified is asphalt road and concrete pavement light whereas loamy soil is used below vegetation layer. Detailed description of Envi-Met database assumptions and equations is provided with free access [25]. The fixed parameters of all scenarios are similar to the 
baseline as presented in Table 3. The baseline model, alternative configuration and additional shading space models layers are provided in Table 4 below, including building and vegetation layers.

Table 2: Vegetation characteristics.

\begin{tabular}{|l|l|c|c|c|}
\hline Symbol & Description & Plant Height & Depth of Root & LAD \\
\hline SK & Tree $15 \mathrm{~m}$ very dense, distinct crown layer Plant type: (Deciduous) & $15 \mathrm{~m}$ & $2 \mathrm{~m}$ & $0.1125<0.2$ \\
\hline T1 & Tree $10 \mathrm{~m}$ very dense, leafless base Plant type: (Deciduous) & $10 \mathrm{~m}$ & $2 \mathrm{~m}$ & $0.075<0.2$ \\
\hline XX & Grass 50 cm aver. dense Plant type: (Grass) & $0.5 \mathrm{~m}$ & $0.5 \mathrm{~m}$ & $0.3<0.5$ \\
\hline
\end{tabular}

Table 3: Baseline Model Assumptions.

\begin{tabular}{|l|l|}
\hline Date & $14^{\text {th }}$ October \\
\hline Wind speed measure at 10m height $(\mathrm{m} / \mathrm{s})$ & 2.57 \\
\hline Wind Direction (degrees from North) & 135 \\
\hline Roughness length at measurement site & 0.1 \\
\hline Initial Temperature of atmosphere $\left({ }^{\circ} \mathrm{C}\right)$ & 37.5 \\
\hline Specific Humidity at model top $(2500 \mathrm{~m}, \mathrm{~g} / \mathrm{kg})$ & 12.45 \\
\hline Relative Humidity in $2 \mathrm{~m}(\%)$ & 40 \\
\hline \hline \multicolumn{2}{|l|}{ Human Parameters for PMV calculations applied to scenarios } \\
\hline Body Parameters & Male, 35 years old, weight $75 \mathrm{~kg}$, height $1.75 \mathrm{~m}$ \\
\hline Clothing Parameter & 0.6 clo \\
\hline Body Metabolism & Basal rate $84.49 \mathrm{~W}$, Work metabolism $80 \mathrm{~W}$ \\
\hline
\end{tabular}

Table 4: comparative models of baseline configuration and alternative configuration.

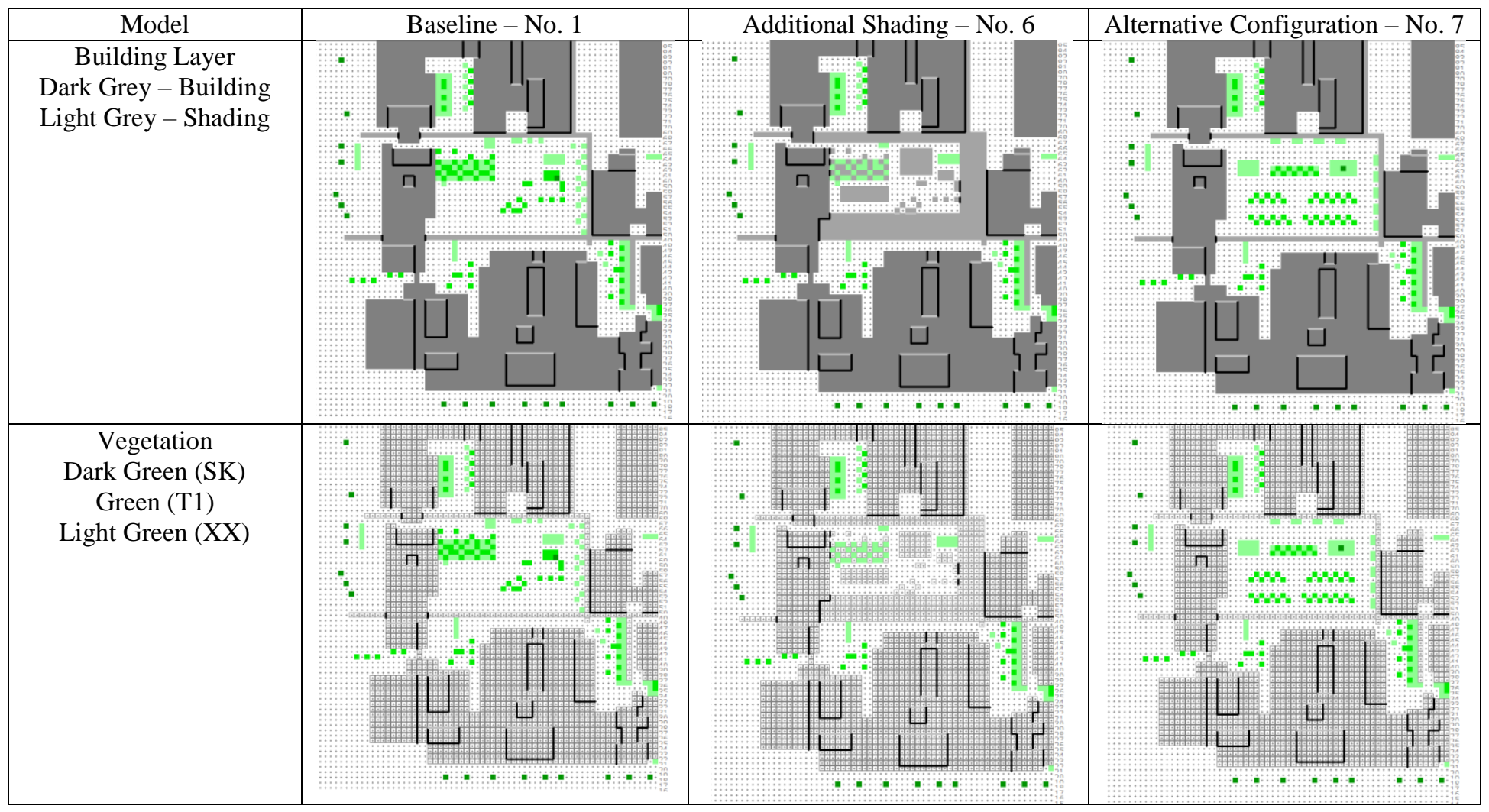




\subsection{Research Limitation}

The baseline model was validated in comparison to actual measurement taken on $14^{\text {th }}$ October 2006 between 10 am and $12 \mathrm{pm}$. Since the complete model initialization data has not been obtained, the default software assumptions were used. Also, the vegetation type has been assumed for this study purposes as stipulated in Section 2.2 above.

The simulation model has indicated similar range of temperature when compared to actual measurements in terms of variations. Minimum and maximum air temperature at $12 \mathrm{am}$ is $36.63^{\circ} \mathrm{C}$ and $39.13^{\circ} \mathrm{C}$ respectively. The air temperature is within the range measured of $36^{\circ} \mathrm{C}$ to $39^{\circ} \mathrm{C}$. The temperature recorded within the courtyard is $55^{\circ} \mathrm{C}$ as per the thermal map in Fig. 3. The simulation results are comparative to those recorded as indicated in the graphical representation in Fig.4.Results (Fig. 5) indicate that surface temperature of shaded vegetated spaces is around $27-28^{\circ} \mathrm{C}$ and that for the hardscape adjacent to vegetation is around $37-40^{\circ} \mathrm{C}$. surface temperature for unshaded hardscape is of average $43^{\circ} \mathrm{C}$ with few spots increasing up to $45^{\circ} \mathrm{C}$. Shaded hardscape surfaces temperature ranges from $35^{\circ} \mathrm{C}$ to $40^{\circ} \mathrm{C}$.

As discussed earlier, the research limitation based on availability of initialization data [24] and site metrological data. The field measurement took place over few hours across the campus, which makes it more difficult to compare an hour by hour scenario. However, the aim is to compare performance between various scenarios and for this, the validation results are considered satisfactory for this research purpose.

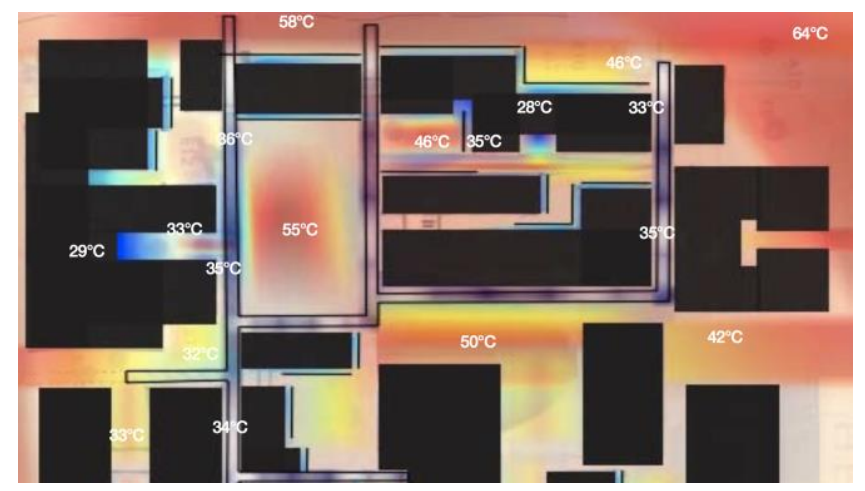

Fig. 3: Thermal map of the campus.

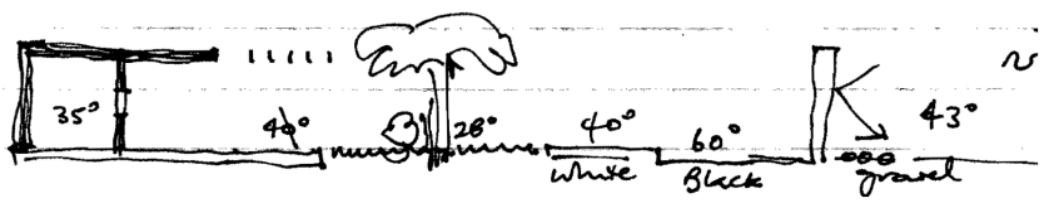

Fig. 4: Recorded temperature variations across campus.
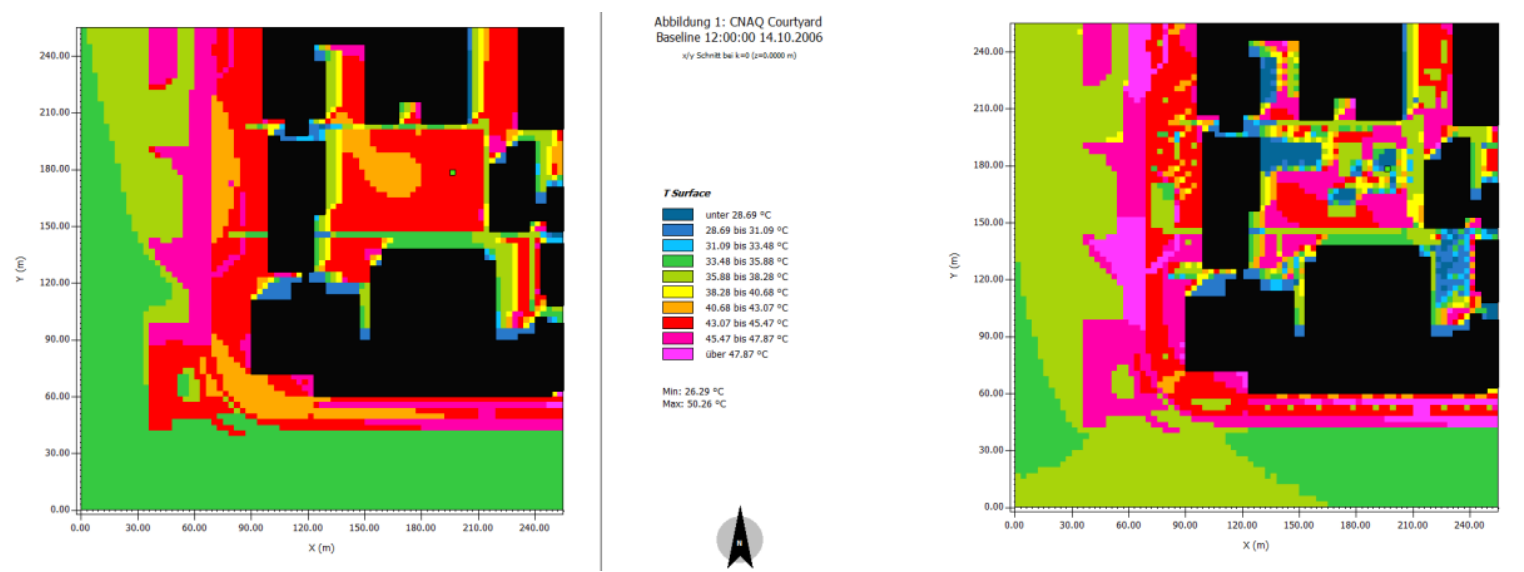

Abbildung 1: CNAQ Courtyard
Baseline 12:00:00 14.10.2006

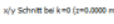

Fig. 5: Hardscape and baseline surface temperature at 12.00 in 14th October (Left: Hardscape, Right: Baseline). 


\section{Results and Discussion}

This section presents the results of the computational modelling with respect to studied impact parameter i.e. Ta, MRT, V and PMV values. Numerical data has been extracted for the courtyard area and used to calculate the total average, maximum, minimum and difference between the maximum and minimum values (delta) for each of the parameters.

\subsection{Air Temperature}

Results indicate various scenarios performing with slight variations between $10 \mathrm{hr}$ and $12 \mathrm{hr}$ as indicated in Fig.6. While the alternative landscape configuration in scenario 7 presents the lowest average air temperature at $10 \mathrm{hr}$, the baseline configuration with $15 \mathrm{~m}$ trees -scenario 4- presents the lowest average Ta at $12 \mathrm{hr}$. In both hours, hardscape scenario -3- presents the highest temperature with a maximum drop in temperature between best and worst scenarios at $0.3^{\circ} \mathrm{C}$

The highest drop in temperature within the individual scenarios setting was witnessed for scenarios 4 with a drop ranging between $0.9^{\circ} \mathrm{C}$ to $1.12^{\circ} \mathrm{C}$ for both studied hours. The results are in line with previous studies where the combined impact of evapotranspiration and shading result in $1^{\circ} \mathrm{C}$ to $3^{\circ} \mathrm{C}$ drop in air temperature depending on the climate and soil conditions [17]. It is important to note that the impact of trees when replaced by a shading structure in scenario 5 and the additional shading in scenario 6 had nearly the same minimum and maximum temperature at $10 \mathrm{hr}$ as the baseline, that is mainly due to the shading from the building envelope being more effective at the low sun angle. However, both scenarios result in slightly higher average temperature at $12 \mathrm{hr}$ compared to the baseline which indicates that the impact of vegetation is more critical at higher ambient temperature. For minimum temperature, the drop in temperature within the baseline courtyard is $0.82^{\circ} \mathrm{C}$ compared to $0.64^{\circ} \mathrm{C}$ for scenario 5 .

The grass replacement of trees within the baseline resulted in slightly higher average temperature up to $0.1^{\circ} \mathrm{C}$ indicating a better performance for a tree and grass combination due to shading impact of trees.

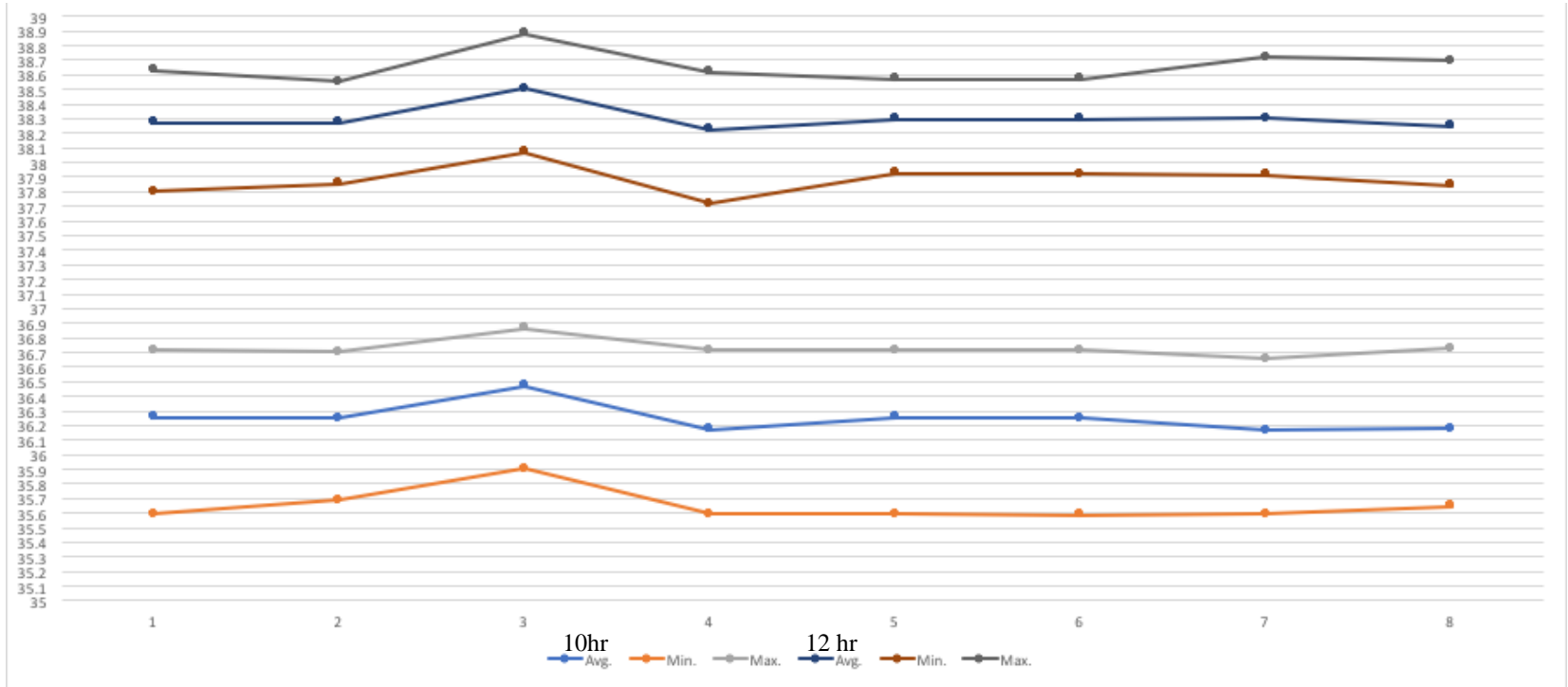

Fig. 6: The impact of studied scenarios on average, maximum and minimum air temperature. 


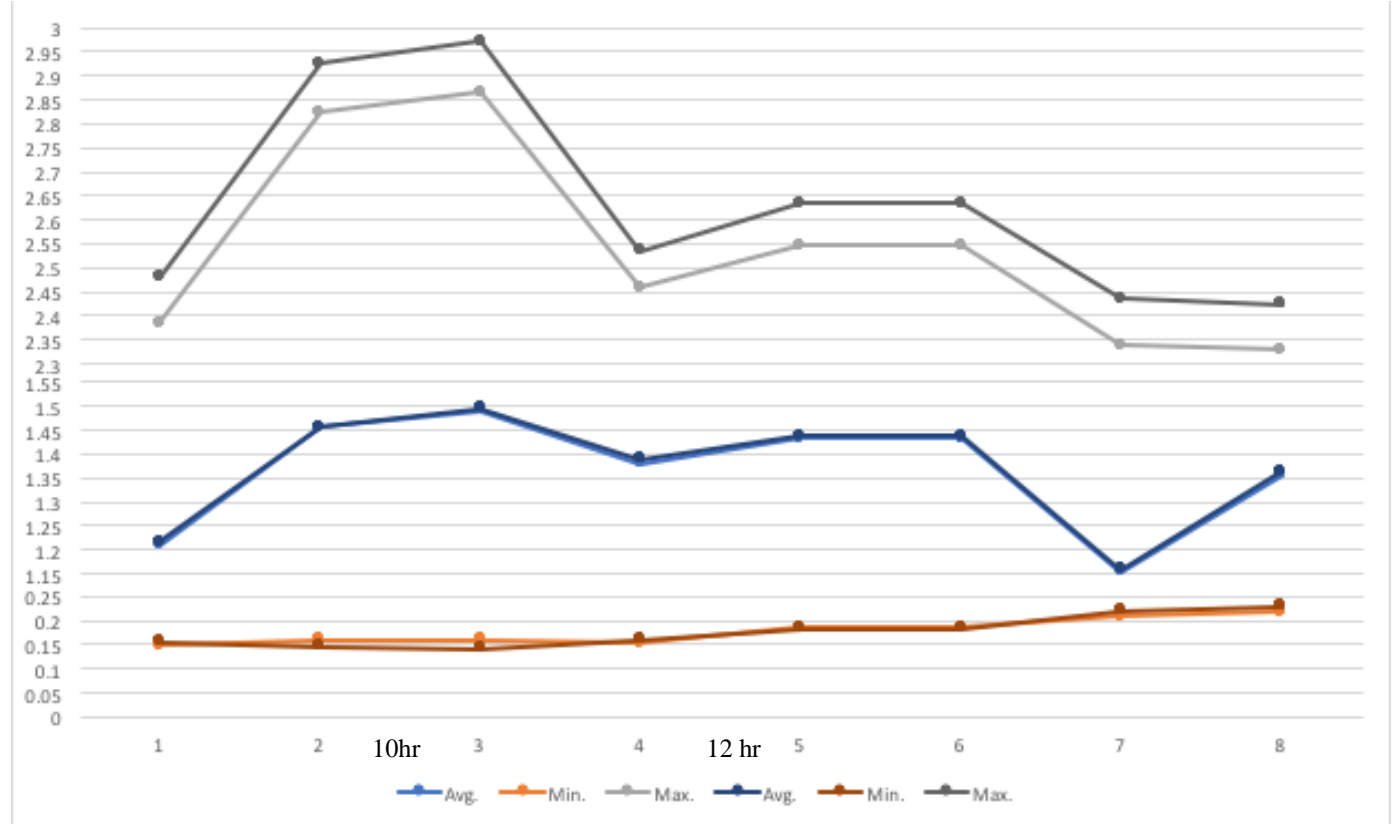

Fig. 7: The impact of studied scenarios on average, maximum and minimum wind speed.

\subsection{Wind Speed}

Since trees present obstacles against air movement, it is important to study the air movement relative to other thermal comfort parameters which will later be presented as part of the PMV discussion. The assessment of wind speed for the 8 scenarios indicates that hardscape only followed by grass only scenarios -3 and 2 respectively-provide the highest average wind speed with an increase of $0.34 \mathrm{~m} / \mathrm{s}$ when compared to the lowest performance witnessed for scenario 7 .

The alternative landscape configuration is based on a more distributed and alternating softscape pattern that occupies the centre of the courtyard rather than the peripheral grouping in the baseline. Therefore, the arrangement indicates more obstacle against the wind flow. It is also noted that the replacement of $10 \mathrm{~m}$ trees in both the baseline and alternative configuration scenario 7 with $15 \mathrm{~m}$ trees in scenarios 4 and 8 present an improved air movement due to the increased tree height. The variations between maximum wind speed between best and worst scenarios exceed $0.5 \mathrm{~m} / \mathrm{s}$ which is relatively significant for hot climate conditions. Refer to Fig.7 for a graphical comparison of the scenarios performance.

\subsection{Mean Radiant Temperature}

Scenario 3 has indicated the highest average MRT for both studied hours - refer to Fig. 8- whereas the best performance was for scenario 7 with a temperature reduction of $4.5^{\circ} \mathrm{C}$ at $10 \mathrm{hr}$ and up to $7.4^{\circ} \mathrm{C}$ at noon. This can be directly related to the shading impact of the softscape as well as surface albedo affecting both short-wave and long-wave radiation.

Scenario 2 indicates the second worst performance, which indicates that using grass only does not have a significant improvement when compared to trees or structural shading. In other words, the impact of shading has a significant contribution to microclimate and specifically MRT reduction which is in line with previous studies $[15,16]$ including Duarte et al where MRT is seen as largely affected by shading through reduction of direct, diffused and reflected shortwave radiation from the sun [17]. 


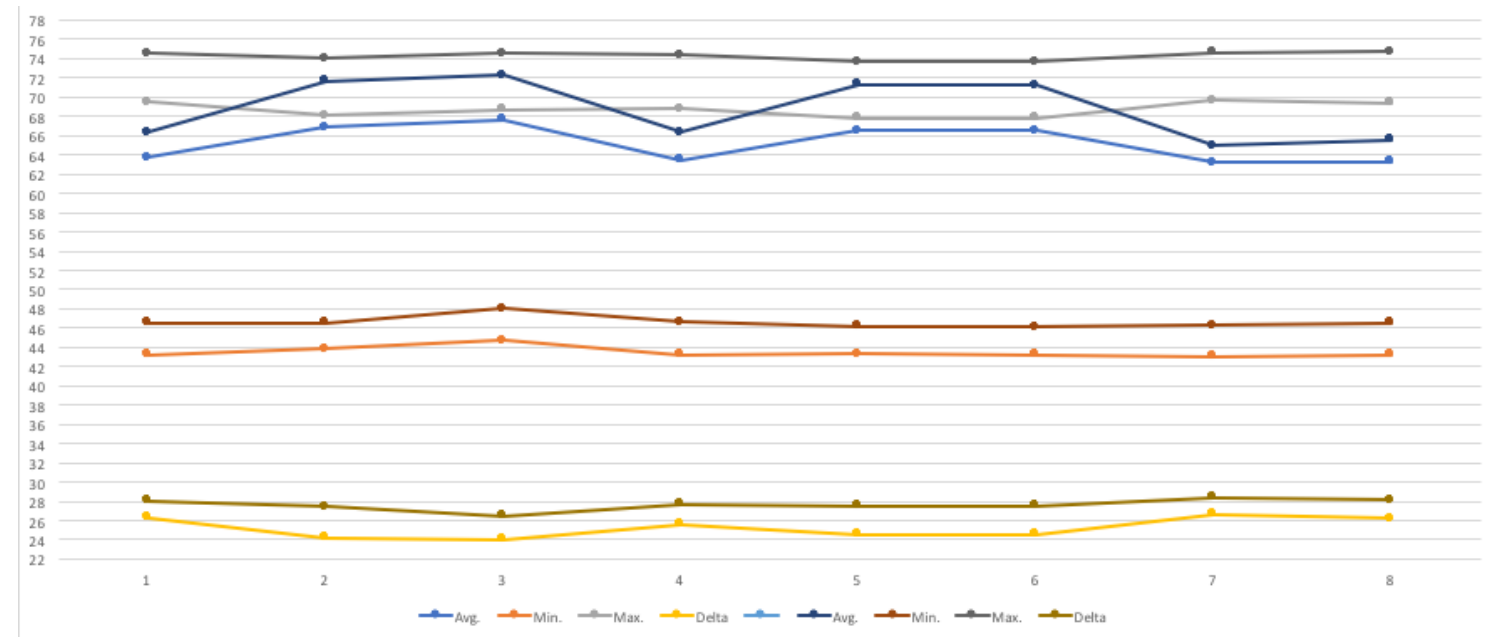

Fig. 8: The impact of studied scenarios on average, maximum and minimum mean radiant temperature.

Scenarios $7 \& 8$ with the alternative landscape configuration results in a lower minimum and average MRT, that is primarily due to a relatively equally distributed vegetation coverage. The arrangement provides shading within the courtyard along with the perimeter shading from the building. However, the same scenarios witness the highest maximum temperature. That can be explained when looking at the wind speed which is the lowest of all scenarios. That is specifically true for the south-west corner of the courtyard which does not have a good wind flow and thus witness the highest temperature in the scenario being blocked by the trees. This results in temperature being absorbed by the surroundings resulting in higher long-wave radiation and thus higher MRT which has also been explained by other studies $[15,16]$.

Additional shading in scenario 6 reduced the maximum temperature compared to the baseline by 1.6 and $0.9^{\circ} \mathrm{C}$ for 10 $\mathrm{hr}$ and $12 \mathrm{hr}$ respectively. However the average temperature increases by 2.8 to $4.8^{\circ} \mathrm{C}$. When studying the direct, diffuse and reflected solar radiation for the baseline and the additional shading scenario, it is noted that both direct and diffused solar radiation is in the same range. However, reflected solar radiation is reduced for the baseline. This explains that looking at maximum temperature, the impact of shading is directly related to the reduction in MRT, whereas on average temperature, vegetation and its impact on reduction of long-wave radiation plays a greater role in reducing the average MRT in the courtyard.

\subsection{Predicted Mean Vote (PMV)}

Envi-met uses a modified PMV model for outdoor environment based on Fanger's 1972 model. The modified model is recognized by the International Organization for Standardization described under ISO 7730 [10], [11]. The Scale ranges from -4 being very cold to +4 being very hot. Based on Bio-met tool description, PMV values may exceed +4 to more than +8 during heat stress time [26]. However, calculated outdoor PMV can still be used to study the effect of air temperature, solar radiation and air velocity on the person's energy balance, and in this research context to explain which strategies are more effective for outdoor thermal comfort.

The results -refer to Fig. 9- indicates a great synergy between the MRT and PMV curves for average and minimum values both at $10 \mathrm{hr}$ and $12 \mathrm{hr}$. The maximum improvement from the hardscape scenario (3) is for scenario 8 at $10 \mathrm{hr}$, and scenario 7 at $12 \mathrm{hr}$ with a reduction in PMV value from 6.07 to 5.67 and 6.9 to 6.26 respectively. It is noticed however, that while the average MRT is relatively higher for scenario 8, PMV is lower. That can be explained due to increased wind speed when the trees are taller as well as less absorption of temperature in the surroundings. The same is true when studying the maximum PMV for those scenarios.

It is noted that the lowest maximum PMV occurs at scenario 4 with a very close performance to that of scenario 8 with an absolute PMV value of 6.32 and 6.33at $10 \mathrm{hr}$, and 7.243 and 7.247 at $12 \mathrm{hr}$ respectively. The key factor to this improvement is wind speed. While at average wind speed, scenario 4 witnesses $0.02 \mathrm{~m} / \mathrm{s}$ air velocity improvement, at maximum speed the difference goes up to $0.13 \mathrm{~m} / \mathrm{s}$ at $10 \mathrm{hr}$ and $0.11 \mathrm{~m} / \mathrm{s}$ at $12 \mathrm{hr}$. 


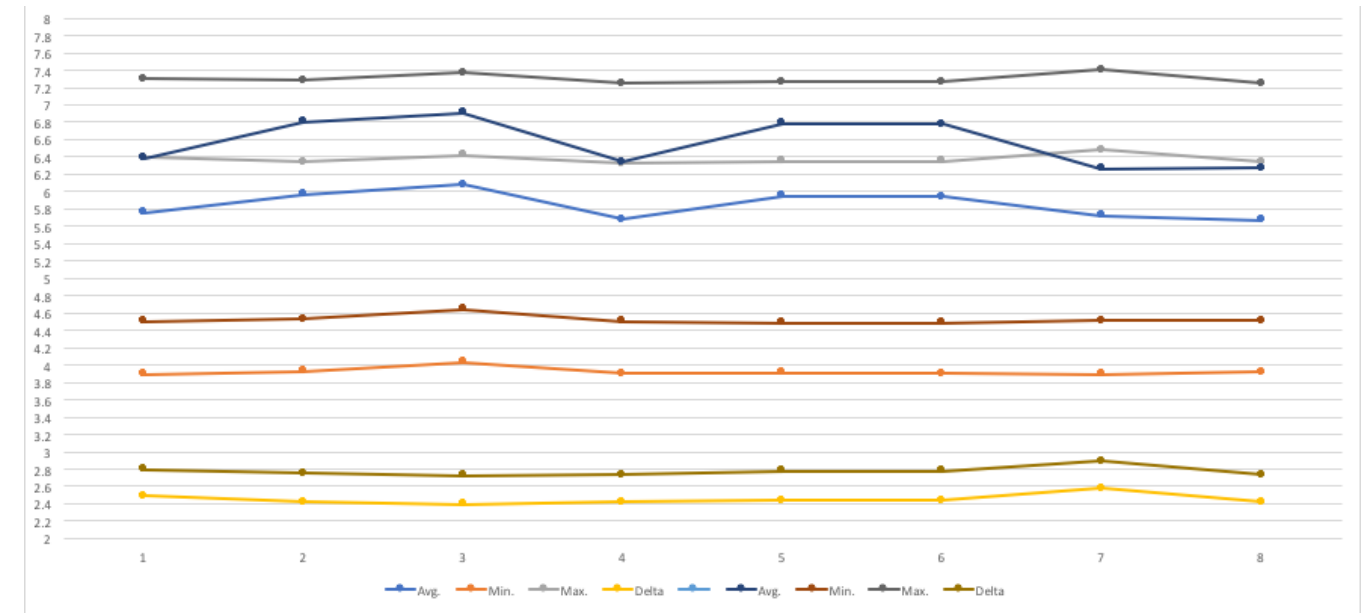

Fig. 9: The impact of studied scenarios on average, $\underset{12 \mathrm{hr}}{\operatorname{hr}}$

\section{Conclusion}

The study used computational modelling to analyse the impact of vegetation on thermal environment. During a hot day, a hardscape only scenario witnesses a maximum increase of $0.3^{\circ} \mathrm{C}$ air temperature when compared to the baseline. The maximum reduction achieved with vegetation is $1.1^{\circ} \mathrm{C}$.

One of the key findings of the study is that for relatively equally distributed vegetation, MRT values are improved when compared to a more concentrated arrangement. However, this arrangement may negatively impact the thermal comfort (studied in PMV values) by obstructing the wind flow and resulting in trapped heat. Therefore, it is critical at high air temperatures to maintain good flow of air movement in conjunction with provision of trees and vegetated coverage.

On average, the alternative configuration results in improvement in both PMV and MRT with a maximum reduction of $7.4^{\circ} \mathrm{C}$ compared to baseline although the wind speed is reduced. A significant reduction of $28.3^{\circ} \mathrm{C}$ is witnessed for scenario 7.

It is also concluded that the same leaf area density type of tree with higher trunk can be more favourable for outdoor thermal comfort in areas where air movement needs to be enhanced. $15 \mathrm{~m}$ Trees provide an average improvement of wind speed of $0.2 \mathrm{~m} / \mathrm{s}$. However, the lower trees help reduce the mean radiant temperature due to its impact on short and long wave radiation. A reduction of $3-5^{\circ} \mathrm{C}$ MRT is attributed to the impact of trees when compared to shading structure due to evapotranspiration effect and an overall reduction in reflected solar radiation within the courtyard.

Further studies are recommended for different conditions, date, humidity and wind direction to test the performance during a peak Summer day as well as testing the thermal comfort using other thermal comfort models such as UTCI.

\section{Acknowledgements}

The authors would like to thank Mr. Ross Donaldson for his support in obtaining data related to the case study.

\section{References}

[1] H. Kusaka, F. Kimura, "The effects of land-use alteration on the sea breeze and daytime heat island in the Tokyo metropolitan area," Journal of. Meteorol. Soc. Jpn., vol. 78, pp. 405-420, 2000.

[2] R. Hamdi, H. Van de Vyver, R. De Troch, P. Termonia, "Assessment of three dynamical urban climate downscaling methods: Brussels's future urban heat island under an A1B emission scenario," International Journal of Climatol., vol. 34, pp. 978-999, 2014.

[3] D. Argüeso, J. Evans, L. Fita, K. Bormann, “Temperature response to future urbanization and climate change," Clim. Dyn., vol. 42, pp. 2183-2199, 2014.

[4] M. Georgescu, P. Morefield, B. Bierwagen, C. Weaver, "Urban adaptation can roll back warming of emerging megapolitan regions," Proc. Natl. Acad. Sci., vol. 111, pp. 2909-2914, 2014.

[5] T. Morakinyo, Y. Lam, "Simulation study on the impact of tree-configuration, planting pattern and wind condition on street-canyon's micro-climate and thermal comfort," Building and Environment, vol. 103, pp. 262-275, 2016. 
[6] Y. Chen, H. Chiu, Y. Su, Y. Wu, K. Cheng, "Does urbanization increase diurnal land surface temperature variation? Evidence and implications," Landscape and Urban Planning, vol. 157, pp. 247-258, 2017.

[7] K. Morris, A. Chan, K. Morris, M. Ooi, M. Oozeer, Y. Abakr, M. Nadzir, I. Mohammed, H. Al-Qrimli, "Impact of urbanization level on the interactions of urban area, the urban climate, and human thermal comfort," Applied Geography, vol. 79, pp. 50-72, 2017.

[8] T. Lin, K. Tsai, R. Hwang, A. Matzarakis, "Quantification of the effect of thermal indices and sky view factor on park attendance," Landscape and Urban Planning, vol. 107, no. 2, pp. 137-146, 2012.

[9] C. Tan, N. Wong, S. Jusuf, "Outdoor mean radiant temperature estimation in the tropical urban environment," Building and Environment, vol. 64, pp. 118-129, 2013.

[10] S. Coccolo, J. Kämpf, J. Scartezzini, D. Pearlmutter, "Outdoor human comfort and thermal stress: A comprehensive review on models and standards," Urban Climate, vol. 18, pp. 33-57, 2016.

[11] International Organization for Standardization, "Ergonomics of the thermal environment: analytical determination and interpretation of thermal comfort using calculation of the PMV and PPD indices and local thermal comfort criteria," ISO 7730, 2005.

[12] P. Höppe, "The physiological equivalent temperature - a universal index for the biometeorological assessment of the thermal environment," International Journal of Biometeorology, vol. 43, no. 2, pp. 71-75, 1999.

[13] D. Fiala, G. Havenith, P. Bröde, B. Kampmann, G. Jendritzky, "UTCI-Fiala multi-node model of human heat transfer and temperature regulation," International Journal of Biometeorol, vol. 56, 429-441, 2012.

[14] H. Staiger, G. Laschewski, A. Grätz, "The perceived temperature - a versatile index for the assessment of the human thermal environment. Part A: scientific basics," International Journal of Biometeorol, vol. 56, 165-176, 2012.

[15] A. Lai, M. Maing, E. Ng, "Observational studies of mean radiant temperature across different outdoor spaces under shaded conditions in densely built environment," Building and Environment, vol. 114, pp. 397-409, 2017.

[16] M. Robitu, M. Musy, C. Inard, D. Groleau, "Modeling the influence of vegetation and water pond on urban microclimate," Solar Energy, vol. 80, no. 4, pp. 435-447, 2006.

[17] D. Duarte, P. Shinzato, C. Gusson, C. Alves, "The impact of vegetation on urban microclimate to counterbalance built density in a subtropical changing climate," Urban Climate, vol. 14, pp. 224-239, 2015.

[18] W. El-Bardisy, M. Fahmy, G. El-Gohary, "Climatic Sensitive Landscape Design: Towards a Better Microclimate through Plantation in Public Schools, Cairo, Egypt," Procedia - Social and Behavioral Sciences, vol. 216, pp. 206216, 2016.

[19] C. Hsieh, F. Jan, L. Zhang, "A simplified assessment of how tree allocation, wind environment, and shading affect human comfort," Urban Forestry \& Urban Greening, vol. 18, pp. 126-137, 2016.

[20] A. Cheshmehzangi, "Multi-spatial environmental performance evaluation towards integrated urban design: A procedural approach with computational simulations," Journal of Cleaner Production, vol. 139, pp. 1085-1093, 2016.

[21] S. Huttner, M. Bruse, "Numerical Modeling of The Urban Climate - A Preview of ENVI-MET 4.0," The seventh International Conference on Urban Climate, Yokohama, Japan, 2009, [Online]. Available: http://www.envimet.com/documents/papers/ICUC7_ModellingV4.pdf

[22] T. E. Morakinyo, Y. F. Lam, "Simulation study on the impact of tree-configuration, planting pattern and wind condition on street-canyon's micro-climate and thermal comfort," Building and Environment, vol. 103, pp. 262-275, 2016.

[23] V. Jernej, R. Jaume, "Evaluation of Environmental Simulation Tools for Assessment of Urban Form Based on Physical Performance," Ph.D. dissertation, Faculty of Architecture, Ljubljana, Slovenia, [Online]. Available: https://docs.google.com/spreadsheets/d/1A2rIx5jTp7XDX6CyrOBukb3JTUw7Ogb3 YyM-FEUahhI/edit\#gid=0

[24] M. Roth, V. H. Lim, "Evaluation of canopy-layer air and mean radiant temperature simulations by a microclimate model over a tropical residential neighbourhood," Building and Environment, vol. 112, pp. 177-189, 2017.

[25] "ENVI-met 3.1 Manual Contents," Envi-met.info, 2017, [Online]. Available: http://www.envimet.info/documents/onlinehelpv3/helpindex.htm

[26] "A holistic Microclimate Model: PMV/PPD," model.envi-met.com, 2017, [Online]. Available: http://www.model.envi-met.com/hg2e/doku.php?id=apps\%3Abiomet_pmv 